ciency the body becomes much more dependent on T3 and the ratio of $\mathrm{T} 3: \mathrm{T} 4$ rises because biosynthesis of $\mathrm{T} 3$ depends on stimulation by thyroid-stimulating hormone to a much greater extent than does that of T4.

It may be the experience of many clinicians, as it has been ours, that a very small group of patients with hypothyroidism are not entirely well on thyroxine replacement alone. It is particularly for these that we have found the T4/T3 tablet of value. There are two other advantages in the use of a mixture of T4/T3 over T4 alone: the first is that should the patient omit to take the tablets it will be quickly apparent and thus likely to be corrected; the second is that for those patients starting for the first time on thyroid replacement therapy the $\mathrm{T} 3$ content will give a rapid response, which is noticeably lacking for a number of days when only $\mathrm{T} 4$ is prescribed. Such replacement therapy should be started with small doses, especially in the presence of myocardial damage.

Many assistants have taken part in this work during the past eight years. Messrs. Glaxo have provided all the preparations used in these trials.

REFERENCES

Braverman, L. E., and Ingbar, S. H. (1964). New England fournal of Medicine, 270, 439.

Farmer, T. A., Smitherman, T. C., Beschi, R. J., and Pittman, J. A. (1969). Fournal of Clinical Endocrinology and Metabolism, 29, 781 .

Pileggi, V. J., Golub, O. J., and Lee, N. D. (1965). Journal of Clinical Endocrinology and Metabolism, 25, 949.

Studer, H., and Greer, M. A. (1966). Die Regulation der Schliddrüsenfunktion bei fodmangel, p. 505. Bern, Huber.

Taylor, S. (1961). Lancet, 1, 341.

Wool, M. S., and Selenkow, H. A. (1965). Clinical Pharmacology and Therapeutics, 6, 710 .

\title{
Gonorrhoea with Skin and Joint Manifestations
}

\section{B. WOLFF, ${ }^{*}$ M.B., M.R.C.P.; HELENA V. GOODMAN, † D.M., F.R.C.S., D.PHYS.MED.; J. VAHRMAN, $\ddagger$ M.B., M.R.C.P.ED., C.P.H.}

\begin{abstract}
Cummary : Three cases of gonorrhoea with pyrexia and $\checkmark$ lesions of the skin and joints (benign gonococcaemia) seen in one hospital group in 1969 within four months of one another are described. All three patients improved rapidly with penicillin therapy. This syndrome is commoner than is usually thought. It must therefore be borne in mind when a diagnosis is in doubt in a patient with unusual skin lesions and joint involvement. Thorough bacteriological investigation is necessary before starting treatment. The relevant literature is reviewed.
\end{abstract}

\section{Introduction}

Gonorrhoea with pyrexia and skin and joint lesions may be termed benign gonococcaemia. It is characterized by mildness of general reaction, skin lesions occurring in crops, and joint involvement. It has often been reported in medical journals of the United States. The British Medical Fournal (1964) reviewed an American article by Abu-Nassar, Hill, Fred, and Yow (1963) and discussed its significance. Soon afterwards O'Sullivan (1964) reported two cases admitted to the infectious diseases unit of the Western Hospital, London. No other reports on benign gonococcaemia have appeared in the British medical press in recent years, apart from one from America (Keil, 1938) and another from Sweden (Björnberg and Gisslén, 1966).

Three cases of this disease were recently diagnosed in hospitals of the Chelsea and Kensington Group. This suggests that the condition is commoner than is usually thought. As it does not appear to be well known in Great Britain, these cases merit recording.

\section{Case 1}

A 20-year-old unmarried woman was admitted to St. Mary Abbots Hospital on 15 January, 1969. Her illness began on 12 January with pyrexia, pain and stiffness of the left shoulder, and pain in the left knee. The following day papules appeared on the extremities, while the joints were less painful. On the 14th she

\footnotetext{
* Medical Registrar, St. Mary Abbots Hospital, London W.8. Present Appointment: Lecturer in Physiology, University of London, King's College, London W.C.2 + Consultant in Physical Medicine and Rheumatology, St. Stephen's
Hospital, London S.W.10. ¥Consultant Physician, Infectious Diseases, the Western Hospital, Lon-
don S.W.6.
}

experienced pain and swelling of her left ankle, and her general practitioner noted that some skin lesions were haemorrhagic.

On admission to hospital she did not appear ill, her temperature was $98.4^{\circ} \mathrm{F}$. $\left(36.9^{\circ} \mathrm{C}\right.$.), and there were no signs of endocarditis. There was swelling of the left knee and ankle with erythema of the skin over the left medial malleolus. Papules and pustules sparsely scattered over the hands, wrists, and feet were each surrounded by an area of erythema. Some of the pustules on the upper extremities were haemorrhagic. On endoscopic examination a moderate amount of white discharge from the cervix was found. She then admitted that she had been sexually promiscuous.

Neisseria gonorrhoeae was isolated from the cervical swab and from blood taken on 16 January. A urethral swab, fluid from the left knee, and pus from a skin lesion taken that day failed to yield $N$. gonorrhoeae. Specimens of blood taken on 18 and 19 January were sterile.

Her temperature varied from $98.4^{\circ} \mathrm{F}$. $\left(36.9^{\circ} \mathrm{C}\right.$.) to $100^{\circ} \mathrm{F}$. $\left(37.8^{\circ} \mathrm{C}\right.$.) from 15 to 17 January, but then became normal. The left shoulder was already painless on admission, while the symptoms and signs in the left knee and ankle disappeared by the 18th. Her right elbow became painful on the 19th, but remained so for only two days. She was treated with benzylpenicillin intramuscularly six-hourly for two weeks, from 21 January until 4 February. Skin lesions continued to appear, though in diminishing numbers, until 27 January.

On 6 February a cervical swab failed to grow $N$. gonorrhoeae. The patient was discharged on 7 February. Wassermann reaction, gonococcal flocculation test, and cervical cultures were negative on 26 March and 19 May. Cervical culture was again negative on 19 June, and there had been no recurrence of symptoms.

\section{Comment}

This patient showed the features most commonly found in benign gonococcaemia-mildness of the systemic reaction, episodes of pyrexia, a migratory arthritis, and typical skin lesions. She had a sustained pyrexia only during the first three days of her admission. Intermittent or sustained pyrexia is often seen in gonococcaemia with skin lesions (Abu-Nassar et al., 1963; Danielsson and Michaëlsson, 1966; Keiser, Ruben, Wolinski, and Kushner, 1968).

The skin lesions in Case 1 were very similar to those described by Abu-Nassar et al. (1963), with papules rapidly evolving into pustules, scanty peripheral distribution, an erythematous area surrounding each lesion, and the haemorrhagic nature of a few of the pustules. This type of skin lesion should make a physician consider gonococcaemia as a possible diagnosis. The skin lesions of Case 1 on the day after her admission to hospital are shown in Figs 1-3. 


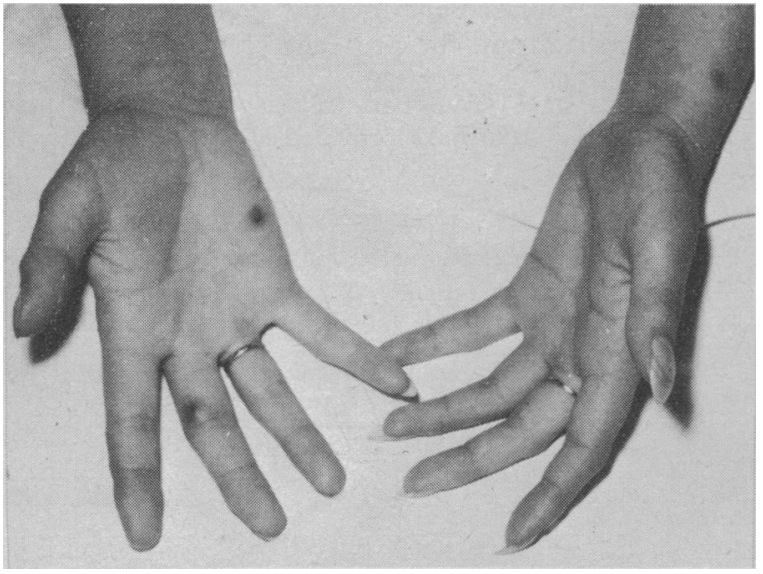

FIG. 1.-Case 1. Photograph of hands and wrists, showing scanty lesions.

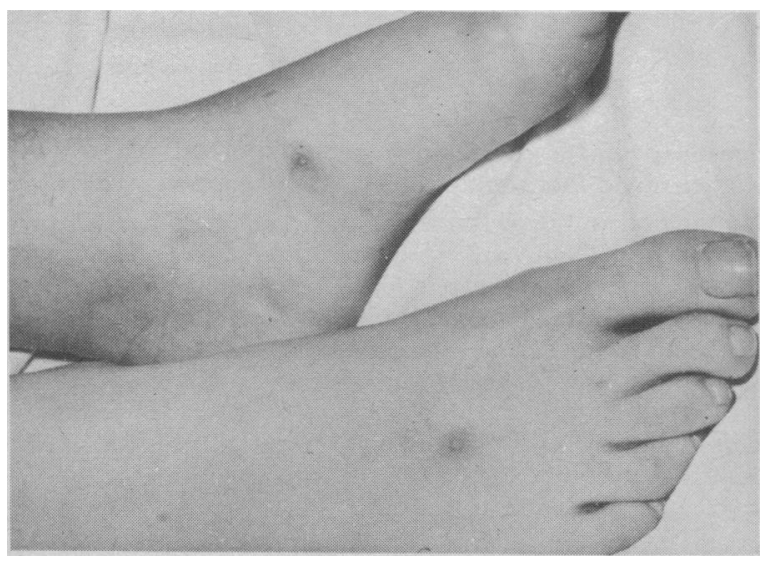

FIG. 2.-Case 1. Photograph of feet, showing papules and pustules.

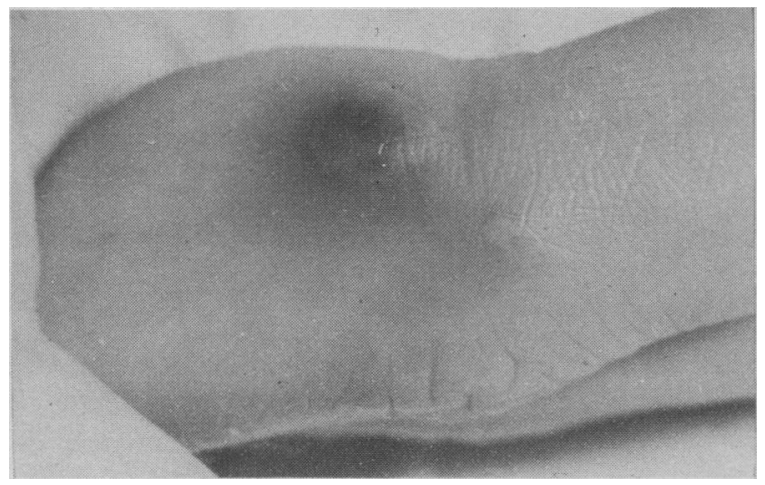

FIG. 3.-Case 1. Close-up view of a typical haemorrhagic pustule on the second finger of the right hand.

\section{Case 2}

A 28-year-old married Jamaican woman, 28 weeks pregnant, was admitted to St. Stephen's Hospital on 8 April, 1969 complaining of pain and swelling of the dorsum of the left foot for five days followed by similar.symptoms in the left wrist, fingers of left hand, and right foot. The day before admission she had developed pain in the right shoulder and right index finger, together with some dysuria and vaginal itching, and had attended the casualty department of a hospital outside her area. She was prescribed ampicillin and referred to St. Stephen's Hospital. When seen she had taken only one capsule of ampicillin, and denied any extramarital sexual intercourse.
On examination she did not appear ill. Her temperature was $99.4^{\circ} \mathrm{F} .\left(37.4^{\circ} \mathrm{C}\right.$.) and pulse 100 . In the cardiovascular system there were no signs of endocarditis. A tender purplish discoloration was present over the dorsum of the right foot, but there was no other skin lesion. The left wrist, metacarpophalangeal joints of both thumbs, proximal interphalangeal joint of right index finger, and left ankle showed soft-tissue swelling and tenderness. The right shoulder was very tender and movement grossly restricted, though no swelling was seen. There was a small effusion in the left knee.

Her Wassermann reaction, Kahn test, and gonococcal flocculation test were negative, and four blood cultures were sterile. Vaginal and urethral swabs on 8 April showed no evidence of $N$. gonorrhoeae. Shortly after her admission the joint symptoms and signs settled, apart from a persistently painful right shoulder with limited movement. Her temperature became normal two days after admission and remained so, apart from an evening pyrexia of up to $99.8^{\circ} \mathrm{F}$. $\left(37.7^{\circ} \mathrm{C}\right.$.) on three occasions $(9,11$, and 26 April). On 5 May her temperature rose to $101^{\circ} \mathrm{F}$. $\left(38.3^{\circ} \mathrm{C}\right.$.) with further multiple joint pains and acute pain and swelling of the proximal interphalangeal joint of the left little finger. A small pustule appeared over this joint, a number of scattered pinhead pustules with erythematous aerolae on the right big toe and right index finger, and some papules on the left calf. Her right shoulder was aspirated and $20 \mathrm{ml}$. of opaque yellow fluid obtained. $N$. gonorrhoeae was isolated from this and also from a second urethral swab taken at the same time. No organisms were grown from the skin lesions or blood, and direct films from skin lesions showed no organisms.

From 6 to 13 May she was given 1 mega unit of penicillin sixhourly intramuscularly, followed by 500,000 units of phenoxymethylpenicillin by mouth six-hourly until 22 May. Two days after treatment was started her temperature was normal and the joint symptoms and skin lesions had disappeared. She was left with some residual stiffness of the right shoulder, which was still improving when she was discharged from hospital on 22 May. She was seen again on 22 August, when she had no symptoms and movements of the right shoulder were full.

\section{Comment}

This patient presented the typical picture of an initial migratory arthritis localizing later to a single joint. Abu-Nassar et al. (1963), in their series of 14 patients with gonococcal skin lesions, found that nine showed polyarticular and four had monarticular manifestations, but in only one of these cases were gonococci recovered from the joint. Keiser et al. (1968) made a clinical distinction between those patients with purulent joint fluid and those with skin lesions. This distinction, however, is not supported by one of their own cases or by Case 2 , as both had skin lesions at the same time as a single septic joint.

Taylor, Bradford, and Patterson (1966) discussed the high proportion of pregnant patients among cases of gonococcal arthritis. In their series of 103 cases 30 (28\%) wcre pregnant.

\section{Case 3}

A man aged 35 was admitted to the Western Hospital on 15 April 1969. On 5 April he had developed pain in the right knee without swelling; the pain was constant and cramp-like in character. On 6 April his temperature rose to $101^{\circ} \mathrm{F} .\left(38.3^{\circ} \mathrm{C}\right.$.) and he felt discomfort in the left knee and left foot. The following day his temperature was $103^{\circ} \mathrm{F}$. $\left(39.4^{\circ} \mathrm{C}\right.$.) and he had malaise, generalized aching, and stiffness. During this time he had taken only analgesic tablets. His temperature then became normal, his general condition improved, and he no longer had joint pains. He was seen on 14 April by his general practitioner, who found a temperature of $101^{\circ} \mathrm{F}$. $\left(38 \cdot 3^{\circ} \mathrm{C}\right.$.) and a rash on his hands.

On admission his general condition was good. His temperature was $99^{\circ} \mathrm{F}$. $\left(37.2^{\circ} \mathrm{C}\right.$.) but soon became normal. Papules were found on his extremities and trunk. These lesions continued to appear until 17 April, and some of them became pustular, though none were ever haemorrhagic. No antibiotics were given; the lesions healed spontaneously, and the pustules crusted. He denied ever having had gonorrhoea or urethritis, though he had been sexually promiscuous. 
He now felt so well that he insisted on going home. He was allowed to do so since all other investigations, including three blood cultures, were negative, even though an area of erythema had appeared on the palmar surface of his right wrist.

When next seen in the outpatient department on 23 April the inflammation over the wrist had increased and was associated with lymphangitis, extending up his forearm and arm. He was therefore readmitted. The next day his temperature was $99^{\circ} \mathrm{F} .\left(37.2^{\circ} \mathrm{C}\right.$.) and new papules had appeared on the limbs and trunk. He still felt relatively well and, as during the first admission, there were no signs of endocarditis.

New pustules had formed on the left hand and there was a large crust on the right elbow which revealed a yellowish discharge when removed. A smear from this showed only debris, and on culture $N$. gonorrhoeae could not be isolated. He was suspected of having gonococcaemia and prostatic massage was decided on. Though little discharge was obtained from the urethra, the organism was cultured from it. While no organisms were found in blood removed just before massage, $N$. gonorrhoeae was grown from blood taken soon after. As he felt well, and there was no sign of endocarditis, he was treated as an outpatient with 500,000 units of penicillin intramuscularly six-hourly from 30 April to 14 May. Within 24 hours of starting of treatment no new lesions appeared and the old lesions healed rapidly. Since then he has not attended hospital.

\section{Comment}

This patient did not have the characteristic haemorrhagic skin lesion. At the beginning of his illness papules and pustules appeared in crops associated with pyrexia, a clinical picture consistent with gonococcaemia or meningococcaemia (Stott and Copeman, 1940). Blood cultures were negative during his first admission. Because he gave no history of gonorrhoea in the past or recent urethritis, and as blood cultures were negative, a bacteriological diagnosis could not be made though it appeared likely that he had a low-grade septicaemia.

It is well established that a bacteraemia may follow various procedures such as operations on the urethra (Barrington and Wright, 1930) and extraction of teeth (Okell and Elliott, 1935). One of us when working in a puerperal sepsis unit found that a transient bacteraemia was common after evacuation of the uterus in patients suffering from septic abortion (Vahrman, unpublished work, 1949). He therefore thought it possible that a positive blood culture might be obtained from Case 3 after prostatic massage. Blood taken immediately before prostatic massage was sterile, but $N$. gonorrhoeae was grown from the specimen of blood removed after this procedure. As no secretion reached the urethral meatus, a swab was inserted into the urethra and from the secretion obtained $N$. gonorrhoeae was isolated. These findings strongly suggest that in this patient the prostate was the source of the gonococcaemia. Ackerman and Calabria (1966) reported a similar case, but the culture was negative though the smear from the urethra of their patient showed intracellular diplococci. Unlike our Case 3 , their patient was known to have had gonorrhoea four years before he developed gonococcaemia.

\section{Bacteriological Methods}

\section{Specimens examined}

Skin Lesions.-Direct smears were made of exudates taken on ordinary cotton-wool swabs and examined after staining by Gram's method. Charcoal-impregnated swabs were also taken and broken immediately into Stuart's (1959) transport medium.

Urethral swabs were taken from all patients and treated in the same way as swabs from skin lesions. In Case 3 this was done after prostatic massage.

Cervical Swabs.-In Case 1 plain and charcoal swabs were obtained from the cervical canal after insertion of a vaginal speculum. Care was taken not to contaminate the specimen with secretion from the vaginal pool. This was treated in the same way as skin and urethral swabs. In Case 2 a vaginal swab was treated in the same manner.

Blood Cultures. $-5 \mathrm{ml}$. of blood was taken with aseptic precautions and inoculated into $50 \mathrm{ml}$. of glucose broth.

foint Aspirates.-Direct smears from knee-joint aspirate from Case 1 and shoulder-joint aspirate from Case 2 were examined after staining by Gram's method, and cultured into Thayer-Martin medium.

\section{Culture Methods}

On reaching the laboratory the swabs in transport medium were inoculated heavily on to Thayer and Martin's (1964) medium. Blood cultures were subcultured to this medium after a preliminary 48-hour incubation in $10 \% \mathrm{CO}_{2}$. All plates were examined after 48 hours' incubation in $10 \% \mathrm{CO}_{2}$ and suspicious colonies were subsequently identified as $N$. gonorrhoeae by biochemical tests.

\section{Discussion}

The two cases of benign gonococcaemia reported by O'Sullivan (1964) and Case 3 described above, came from the Western Hospital; that is three of the five cases in the same hospital group were treated in one hospital during the past five years. The condition may therefore be commoner than the absence of-reports suggests. Spontaneous recovery, an event not rare in pre-antibiotic times, or suppression of the disease by antibiotics before a diagnosis is made, could account for its apparent rarity in hospital practice.

Before the discovery of antibiotics the occurrence of this syndrome in males was not uncommon. For example, three out of five patients of Keil (1938) were male. Recent reports indicate that it has become rarer in them: 2 out of 14 patients of Abu-Nassar et al. (1963), one out of nine patients of Björnberg and Gisslén (1966) and none of the patients of Keiser et al. (1968) were male. This may be because males now usually receive specific treatment for urethritis, unlike females, who are often asymptomatic. Ackerman and Calabria (1966) reported a case of benign gonococcaemia in a male without urethritis, like Case 3 . They reviewed the literature and concluded that this syndrome without urethritis was rare.

\section{Diagnosis}

The diagnosis of benign gonococcaemia should be considered in any patient with unusual lesions of the joints and skin, though there may be no evidence of urethritis or a history of sexual risk. An attempt should be made to confirm the diagnosis bacteriologically. The Table, derived from reported cases, shows the frequency with which $\mathrm{N}$. gonorrhoeae was isolated from various sites. In most cases the organism can be isolated from the urethra or cervix in females and from the urethra in males if suitable technique is used. Blood culture should be done on a number of occasions, but is not so likely to be positive unless carried out after prostatic massage or cervical swabbing.

Arthritis.-Joint stiffness persisted in Case 2 after improvement of all other symptoms. This is not an uncommon finding, though bony destruction is rare even with purulent effusions (Keiser et al., 1968; Partain, Cathcart, and Cohen, 1968). Joint symptoms may be minimal as in Case 3. Our three cases, which showed arthralgia, monarthritis, and polyarthritis, illustrate the variability of joint involvement. The septic type of gonorrhoeal arthritis is not difficult to diagnose because the patients are very ill, the joint pain is acute, and 
Summary from the Literature of Bacteriological Findings in Reported Cases of Benign Gonococcaemia

\begin{tabular}{|c|c|c|c|c|c|}
\hline & \multirow{2}{*}{$\begin{array}{c}\text { No. } \\
\text { of } \\
\text { Cases }\end{array}$} & \multirow{2}{*}{$\begin{array}{l}\text { Cervix } \\
\text { and/or } \\
\text { Urethra. } \\
\text { Smear or } \\
\text { Culture }\end{array}$} & \multirow{2}{*}{$\begin{array}{l}\text { Blood } \\
\text { Culture }\end{array}$} & \multicolumn{2}{|c|}{ Skin Lesions } \\
\hline & & & & Smear & Culture \\
\hline $\begin{array}{l}\text { Abu-Nassar et al. (1963) } \\
\text { O'Sullivan (1964) } \\
\text { Fred et al. (1965) } \\
\text { Ackerman et al. (1965) } \\
\text { Ackerman and Calabria (1966) } \\
\text { Björnberg and Gisslén (1966) }\end{array}$ & $\begin{array}{r}14 \\
2 \\
6 \\
1 \\
1 \\
9\end{array}$ & $\begin{array}{ll}10 \text { of } & 12 * \\
2 \text { of } & 2 \\
6 \text { of } & 6+ \\
0 \text { of } & 1 \\
1 \text { of } & 1 \\
9 \text { of } & 9\end{array}$ & $\begin{array}{l}0 \text { of } 11 \\
0 \text { of } \\
0 \text { of } \\
1 \text { of } \\
1 \text { of } 1 \\
1 \text { of } \\
1\end{array}$ & $\begin{array}{ll}6 \text { of } & 7 \\
0 \text { of } & 1 \\
3 \text { of } & 3 \neq \\
1 \text { of } & 1 \$ \\
1 \text { of } & 1 \\
- & \end{array}$ & $\begin{array}{l}0 \text { of } \\
0 \text { of } \\
1 \text { of } \\
0 \text { of } \\
0 \text { of } \\
0 \text { of } \\
7\end{array}$ \\
\hline $\begin{array}{l}\text { Danielsson and Michaëlsson } \\
(1966)\end{array}$ & 3 & 3 of 3 & 0 of 1 & 1 of 1 & 0 of \\
\hline $\begin{array}{l}\text { Frichot and Everett (1967) } \\
\text { Keiser et al. (1968) (Cases with }\end{array}$ & 1 & 0 of 1 & 0 of 1 & & 1 of \\
\hline skin lesions) & 15 & 11 of 14 & 5 of 12 & 3 of 8 & 0 of 11 \\
\hline $\begin{array}{l}\text { Grossman and Koos (1968) } \\
\text { Present Series }\end{array}$ & 3 & 3 of 3 & $\begin{array}{l}1 \text { of } 1 \\
2 \text { of } 3\end{array}$ & 0 of 3 & $\begin{array}{l}0 \text { of } 1 \\
0 \text { of }\end{array}$ \\
\hline Totals & 56 & 46 of 53 & 11 of 39 & 15 of 25 & 2 of 41 \\
\hline$\%$ Positive in each category & & 87 & 28 & 60 & 5 \\
\hline
\end{tabular}

*Approximate figure, as paper merely states that 5 out of 11 cultures and 10 out of 12 smears were positive.

tThis figure is implied but not stated.

The paper states, "Histology and Gram-staining suggestive."

SDemonstrated histologically only.

skin lesions are not usually present. The rapid response of the benign type to penicillin in adequate dosage is characteristic of the disease and distinguishes it from Reiter's disease (Partain et al., 1968).

Skin Lesions.-When the lesions are haemorrhagic and appear mainly on the distal parts of the extremities, the diagnosis is more likely to be considered than when the eruption is non-specific, consisting of papules and pustules generally distributed as in Case 3. Other types of skin lesion have been reported, such as purpura (Abu-Nassar et al., 1963), painful reddened areas (Danielsson and Michaëlsson, 1966), and erythema-nodosum-like lesions with central papules (Grossman and Roos, 1968). The last should be distinguished from erythema nodosum due to other causes. Chronic meningococcaemia and low-grade staphylococcal septicaemia may be indistinguishable from benign gonococcaemia.

\section{Treatment}

Our three cases responded rapidly to treatment with penicillin. The optimum dose is not known, but it seems logical to use a large one intramuscularly for two weeks to ensure elimination of the organisms from all foci. Too small a dose may result in the carrier state or, by suppressing the organism, make diagnosis difficult.

We wish to thank Dr. B. Gottlieb, consultant physician at St. Mary Abbots Hospital, for permission to publish details of Case 1 and for advice in the preparation of this paper. We also wish to thank Dr. M. Patricia Jevons, consultant bacteriologist at St. Stephen's Hospital, for writing the section on bacteriology which she had carried out.

ADDENDUM.-Since this paper was written another patient with benign gonococcaemia was admitted to the Western Hospital, on 13 October 1969. She was a girl, aged 19, who had had an intermittent pustular eruption of her legs and rectirrent painful swelling of both her ankles for six months. $N$. gonorrhoeae was isolated from the cervix and the blood. The blood had been taken soon after the cervix had been swabbed.

\section{REFERENCES}

Abu-Nassar, H., Hill, N., Fred, H. L., and Yow, E. M. (1963). Archives of Internal Medicine, 112, 731.

Ackerman, A. B., and Calabria, R. (1966). Fourmal of the American Medical Association, 196, 101

Ackerman, A. B., Miller, R. C., and Shapiro, L. (1965). Archives of Dermatology, 91, 227.

Barrington, F. J. F., and Wright, H. D. (1930). Fournal of Pathology and Bacteriology, 33, 871.

Björnberg, A., and Gisslén, H. (1966). British fournal of Venereal Disease, 42, 100.

British Medical fournal, 1964, 1, 923.

Danielsson, D., and Michaëlsson, G. (1966). Acta Dermato-venereologica, 46, 257.

Fred, H. L., Eiband, J. M., Martincheck, L. A., and Yow, E. M. (1965). Archives of Internal Medicine, 115, 191. Frichot, B. C., and Everett, M. A. (1967). Foumal of the Oklahoma State
Medical Association, 60, 597.

Grossman, J., and Roos, R. (1968). New England fournal of Medicine, 279, 721 .

Keil, H. (1938). Quarterly Fournal of Medicine, 7, 1.

Keiser, H., Ruben, F. L., Wolinski, E., and Kushner, I. (1968). New England fournal of Medicine, 279, 234.

Okell, C. C., and Elliott, S. D. (1935). Lancet, 2, 869.

O'Sullivan, E. P. (1964). British Medical fournal, 1, 1508.

Partain, J. O., Cathcart, E. S., and Cohen, A. S. (1968). Annals of the Rheumatic Diseases, 27, 156.

Stott, A. W., and Copeman, W. S. C. (1940). Lancet, 1, 1116.

Stuart, R. D. (1959). Public Health Reports, 74, 431.

Taylor, H. A., Bradford, S. A., and Patterson, S. P. (1966). Obstetrics and Gynecology, 27, 776.

Thayer, J. D., and Martin, J. E., jun. (1964). Public Health Reports, 79, 49.

\section{Thyroid-stimulating Hormone Response to Synthetic Thyrotrophin Releasing Hormone in Man}

British Medical fournal, 1970, 2, 274-277 in some cases. The only side-effect noted was transient nausea with doses greater than $50 \mu \mathrm{g}$. Measurement of serum T.S.H. levels after administration of thyrotrophin-releasing hormone should prove a useful test of pituitary T.S.H. release and may help to distinguish pituitary and hypothalamic lesions.

\section{INTRODUCTION}

There is now clear evidence that the hypothalamus produces a regulating substance, thyrotrophin-releasing hormone, which controls the release of thyroid-stimulating hormone (T.S.H.) from the anterior pituitary. The releasing hormone is stored in the median eminence of the hypothalamus and released into the portal blood system which flows from the hypothalamus to the pars distalis of the anterior pituitary (Harris, 1955; Martini and Ganong, 1967). The release of T.S.H. from the pituitary is stimulated by thyrotrophin- 